\title{
Neurological manifestations in a patient with visceral leishmaniasis
}

\author{
B Karak, R K Garg, S Misra, A M Sharma
}

A 20-year-old man with visceral leishmaniasis receiving sodium stibogluconate therapy presented with left earache, skin eruptions over the left ear and side of the neck, inability to close the left eye, dribbling of saliva through the left side of the mouth, facial asymmetry with slurring of speech and hearing impairment (left ear) for two weeks. Four days later he also experienced marked unsteadiness of gait and falling towards the left while walking. Eruptions gradually subsided, pain decreased, but scars were left (figure).

On examination, the patient had scanning type of dysarthia and left-sided gaze-evoked nystagmus. Corneal reflex on the left side was absent. There was lower motor neuron type of facial palsy along with loss of taste over the left half of the anterior two thirds of the tongue. The patient had left-sided neural deafness and marked gait ataxia. Heel-shin test and finger-nose test on the left side were markedly impaired. All superficial reflexes were present and plantars were flexor. Haematological, serum biochemical parameters and urinalysis were normal. Chest X-ray, electrocardiogram, computed tomography and magnetic resonance imaging of the head were also normal.

\author{
Department of \\ Neurology, Institute of \\ Medical Sciences, \\ Banaras Hindu \\ University, Varanasi \\ 221005, India \\ B Karak \\ R K Garg \\ S Misra \\ A M Sharma
}

Accepted 21 January 1998

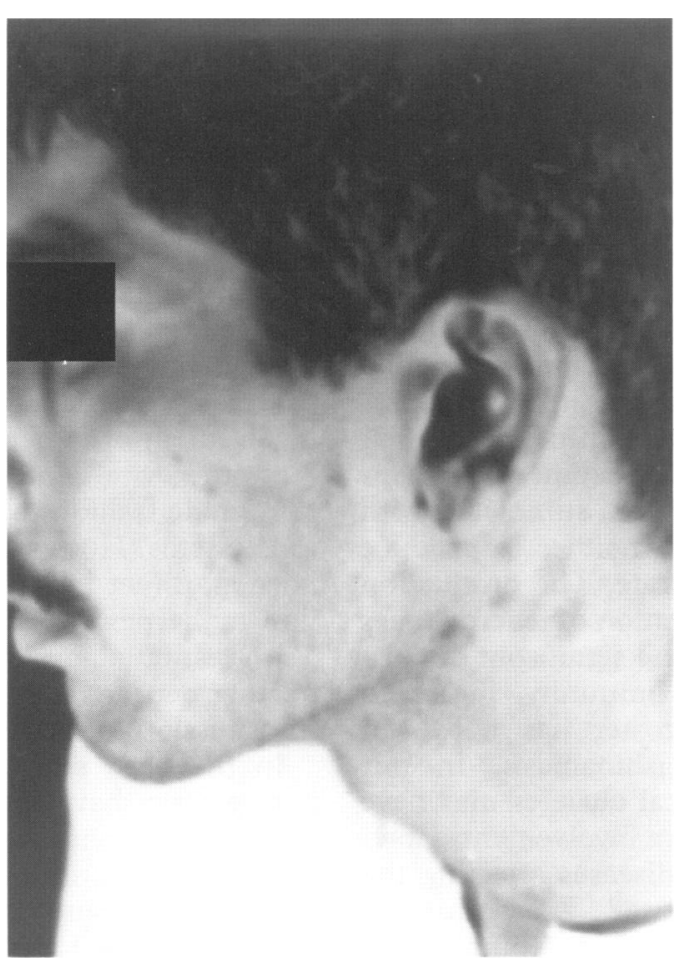

\section{Questions}

1 What is the most likely diagnosis?

2 What other neurological complications may be expected? 


\section{Answers}

QUESTION 1

Rash on the pinna and external auditory meatus, along with involvement of 7 th and 8 th cranial nerves, is consistent with the diagnosis of herpes zoster oticus (Ramsey-Hunt syndrome). In this case, in addition there was involvement of the ophthalmic division of the 5 th and upper cervical nerves. Another neurological complication present in this case is ipsilateral cerebellar involvement.

QUESTION 2

Other neurological manifestations of herpes zoster are given in the box.

\section{Discussion}

In herpes zoster, eruptions are usually unilateral and involve a single dermatome. Dissemination occurs in $2-10 \%$ of patients. The highest frequency of dissemination occurs in those with malignant disease or in immunocompromised patients such as those with acquired immune deficiency state (AIDS). In fact, dissemination reflects a state of viraemia, defined as more than 20 lesions outside the primary and adjacent dermatome. ${ }^{1}$ In our patient the disease was not truly disseminated, but he had extensive cephalic involvement (trigeminal therpes zoster opticus + upper cervical) along with unilateral cerebellar involvement.

The patient had visceral leishmaniasis and was receiving stibogluconate therapy. $\mathrm{He}$ was resident in Bihar state, an area highly endemic area for visceral leishmaniasis. He had all the important characteristics of the disease: fever, hepatosplenomegaly, anaemia and leucopenia. This disease primarily affects the lymphoreticular system, and depression of the cellular immune response is well documented. Lymphocytes from such patients, stimulated with leishmania antigen, neither produce interleukin-2 nor proliferate. The production of interferon- $\gamma$, and activation of macrophages are also impaired. ${ }^{3}$ Despite significant impairment of cell-mediated immunity, increased occurrence of herpes zoster has not been reported in visceral leishmaniasis. In our patient the immunological changes may have resulted in more extensive involvement. However, in other systemic diseases affecting the immune system, increased association of zoster is well documented. ${ }^{34}$ Goffinet and co-workers ${ }^{3}$ found herpes zoster in $11.4 \%$ of lymphoma patients. An increased frequency of zoster occurred in these patients after splenectomy or chemotherapy and following radiation therapy. In another study, Schimpff and co-workers ${ }^{4}$ reported zoster in $25 \%$ of patients with Hodgkin's disease, $7 \%$ of other lymphoma patients, $1.2 \%$ of patients with acute leukaemia, and $1.8 \%$ of patients with solid tumours. The increased occurrence of herpes zoster in patients with AIDS suggests the major role of cell-mediated immunity in preventing the occurrence of the disease. Reactivation of herpes zoster is seen in $1-20 \%$ of patients with HIV infection; this is an indi-
Neurological manifestations of herpes zoster

Post-herpetic neuralgia

Motor neuropathies

Cranial

- Ramsay-Hunt syndrome (VII, VIII)

- ophthalmoplegia (III, IV, VI)

- others (II, V, IX, X, XI, XII)

Peripheral

- diaphragmatic

- neurogenic bladder

- Guillain Barre syndrome

- herpes zoster radiculitis (in AIDS)

- sensory ataxic neuropathies (in AIDS)

Central

- transverse myelitis

- encephalitis

- meningoencephalitis

- cerebrovasculopathy (granulomatous angiitis)

cation of decline in immune function, and is often the first clinical indication of immunodeficiency. ${ }^{5}$

The most unusual feature in our patient was ipsilateral cerebellar involvement. Acute cerebellitis is an important and common complication of varicella infection of childhood (chicken pox). Cerebellar involvement in varicella is bilateral and self-limiting, usually resolving within two weeks. ${ }^{1}$ In these children, the aetiology of cerebellar involvement (direct invasion or auto-immune reaction) is unresolved. Ipsilateral involvement of the cerebellum suggests intracranial transmission of viral infection and/or inflammation (angiitis) of vessels of the posterior circulation. The involvement of upper cervical nerves suggests that the viral infection is carried in a retrograde fashion to the vertebrobasilar arterial systems. However, as imaging studies are normal, direct invasion of ipsilateral cerebellum by herpes zoster virus is more plausible. The vestibulolabyrinthine system and connecting neurons may serve as a route of viral transmission to the cerebellum.

In the past, several cases of contralateral hemiparesis have been reported after the eruption of ophthalmic zoster; $50 \%$ of such patients were immunologically impaired and many had granulomatous angiitis of the cerebral vessels. Virus-like particles were identified in vessel walls in several autopsy studies. These studies suggested that the cerebral infarctions in association with herpes zoster were a direct result of viral invasion of cerebral vessel leading to inflammation, thrombosis and distal infarction. Angiograms showed ipsilateral segmental stenosis of the supraclinoid portion of the internal carotid artery. Extensions of the trigeminal nerve probably serve as a route of virus transmission to intracranial vessels. ${ }^{18}$

One of the major goals of treatment of herpes zoster is to prevent dissemination of virus. Intravenous or high-dose oral acyclovir is the treatment of choice. Immunocompromised 
patients with dissemination of virus and seriously ill patients with herpes zoster ophthalmicus need intravenous acyclovir. ${ }^{5}$ Possibly, the reversal of his immune-deficient state with stibogluconate resulted in the good recovery of our patient, even without treatment with acyclovir.

1 Straus SE, Ostrove JM, Inchauspe G, et al. Varicella-zoster virus infection: biology, natural history, treatment and vrevention. Ann Intern Med 1988;108:221-37.

2 Carvalho EM, Barral A, Pedral-Sampaio D, et al. Immuno2 Carvalho EM, Barral A, Pedral-Sampaio $\mathrm{D}$, et al. Immunologic markers of clinical evolution in children recently
infected with Leishmania donovani chagasi. $\mathcal{F}$ Infect Dis infected with Leish

3 Goffinet DR, Glastein EJ, Merigan TC. Herpes zostervaricella infections and Iymphoma. Ann Intern Med 1972;76:235-40.

4 Schimpff NJ, Serpick A, Stoler B, et al. Varicella zoster infection in patients with cancer. Ann Intern Med 1972;76: 241-54.

\section{Final diagnosis}

Extensive cephalic herpes zoster with ipsilateral cerebellar involvement in a patient with visceral leishmaniasis.

Keywords: leishmaniasis; herpes zoster

5 Fauci AS, Lane HC. Human immuno-deficiency virus (HIV) disease: AIDS and related disorders. In: Isselbacher KT, Braunwald E, Wilson JD, et al eds, Harrison's Principles of internal medicine, 15th edn, Vol II. New York: McGrawof internal medicine, 15th

6 Snow BJ, Simcock JP. Brainstem infarction following cervical herpes zoster. Neurology 1988;38:131.

7 Leinneman CC, Alvira MM. Pathogenesis of VZ angiitis in the CNS. Arch Neurol 1980;37:239-40.

8 Reshef E, Greenberg SB, Jankovic J. Herpes zoster ophthalmicus followed by contra lateral hemiparesis. Report of two cases and review of literature. $\mathcal{F}$ Neurol Neurosurg Psychiatry $1985 ; 48: 122-7$.

\title{
Abdominal pain in a patient with falciparum malaria
}

\author{
P S A Sarma, R Shashi Kumar
}

A 17-year-old native Central Indian man was hospitalised with constant abdominal pain accompanied by fever, chill, sweats and vomiting of 4 days duration. He was unemployed, and did not use tobacco, alcohol or illicit drugs. There was no history of biliary tract disease or lipid disorders, malaria or use of steroids or antimalarial drugs. On examination, he was found to be alert, febrile $\left(38^{\circ} \mathrm{C}\right)$, jaundiced, and normotensive. Epigastric tenderness and mild generalised abdominal distension with reduced intestinal peristaltic sounds were noted. Laboratory studies showed: haemoglobin $9.8 \mathrm{~g} / \mathrm{dl}$, leucocyte count $11.8 \times 10^{9} / 1$ (polymorphs $73 \%$ ), erythrocyte sedimentation rate $28 \mathrm{~mm} / \mathrm{h}$, and haematocrit $29 \%$. Blood urea nitrogen was $7.2 \mathrm{mmol} / \mathrm{l}$, creatinine $145 \mu \mathrm{mol} / \mathrm{l}$, and serum electrolytes, cholesterol, and triglycerides were normal. Liver function tests showed a total bilirubin value of $31 \mu \mathrm{mol} / 1$, and minimally raised hepatic enzymes (aspartate aminotrans-

Department of Medicine, Jawaharlal Nehru Hospital and Research Centre, Bhilainagar, Madhya Pradesh 490006, India P S A Sarma

R S Kumar

Correspondence to Dr P S A Sarma, MIG II - 437, Hudco, Amdinagar Bhilainagar, Madhya Pradesh, PIN 490006, India

Accepted 21 January 1998 ferase $84 \mathrm{U} / \mathrm{l}$, alanine aminotransferase $70 \mathrm{U} / \mathrm{l})$. Hyperamylasaemia $(2132 \mathrm{U} / \mathrm{l})$, hypocalcaemia $(1.9 \mathrm{mmol} / \mathrm{l})$, and hypoalbuminaemia $(32 \mathrm{~g} / \mathrm{l})$ were detected. Urinary amylase levels were raised to $4011 \mathrm{U} / 1$. A Leishman-stained peripheral blood smear demonstrated several ring-form trophozoites of Plasmodium falciparum (1.5\% of parasitaemia). The electrocardiogram showed normal sinus rhythm. The red blood sickling, and antinuclear antibody tests were negative. An abdominal X-ray showed mild generalised ileus without air-fluid levels. Ultrasound demonstrated an oedematous, enlarged pancreas.

\section{Questions}

1 What is the most likely diagnosis?

2 How does abdominal pain manifest in falciparum malaria?

3 List the infectious causes of acute pancreatitis. 